\title{
Trade-off Analysis and Design of a High Power Density PM Machine for Flooded Industrial Pump
}

\author{
A. Al-Timimy, M. Degano, Z. Xu, G. Lo Calzo, \\ P. Giangrande, M. Galea, C. Gerada, He Zhang \\ School of Electrical Engineering \\ University of Nottingham \\ Nottingham, UK, NG7 2RD \\ eexaa146@nottingham.ac.uk
}

\author{
L. Xia \\ AVIC Flight Automatic Control Research Institute \\ China \\ cd@facri.com
}

\begin{abstract}
This paper presents the trade-off analysis and design of a high power-density machine for industrial pump applications. The developed permanent magnet synchronous machine drives an electric, oil flooded pump. Different slot/pole combination and winding configuration have been investigated in order to identify the optimal combination that satisfies the electromagnetic and thermal constraint while keeping the losses as small as possible. Several strategies such as the use of the Cobalt iron material for the stator core lamination and the adoption of Halbach array have been investigated in this work to improve the performance capabilities of the designed machine. The electromagnetic performances have been evaluated by using a finite element method. Thermal behaviour has been determined using a lumped parameter network. The outcome of the thermal analysis helped to identify the optimal cooling configurations. The final results are presented highlighting the achieved design targets.
\end{abstract}

\section{INTRODUCTION}

The thermal limit is one of the most important constraints on the performance of electrical machine design [1]. This could be significantly improved by advanced cooling methods and thus higher torque and power densities can be achieved [1, 2]. For high performance applications where the constraints such as the envelope size and mass are important, the machine design needs to achieve high power density and thus advanced thermal design and management is required [1].

Several thermal management systems exist and the application of the cooling strategy is dependent on the operation condition and environment of the machine [3]. For a motor-driven pump, one of the most convenient methods to cool the machine is to use the oil of the pumping system, which gives excellent cooling capabilities [3]. However, the added cooling capability due to flooded machines is still not enough to guarantee an optimal electrical machine performance, especially in terms of high power, reliability, cost-effectiveness and efficiency [4].

Considering the high power to mass and power to volume ratio associated with this application, in addition to the constraints on the available space and mass, different machine topologies have been investigated [4]. In order to satisfy the requirements of the project, one of the best machine technologies available today is that of the Permanent Magnet
Synchronous Machines (PMSM) [4, 5]. In fact, PMSMs have significant advantages compared to other types of electric motors such as higher torque and power density, higher efficiency, simple structure and low maintenance [6]. From the initial trade-off study, an 8-pole/9-slot PMSM has been identified as the most promising topology.

The main objectives of this work are to achieve a machine design used to drive an oil-flooded pump for a harsh environment application where torque, efficiency and thermal constraints are considered the main design objectives.

\section{DESIGN REGUIREMENTS AND CONSTRAINTS}

This section presents the required specifications for the electrical drive (electrical machine, power converter and control system) which will drive the flooded pump.

\section{A. Electromagnetic Performance and Geometry}

Fig.1 shows the torque-speed characteristics of the electrical machine. A maximum continuous torque has to be delivered within a speed range from 0 to $8700 \mathrm{rpm}$. Beyond the base speed of $8700 \mathrm{rpm}$, flux weakening is required until the maximum speed of $19000 \mathrm{rpm}$. The machine design needs to fulfil several constraints, such as the geometrical dimensions due to the restrained available space and the active parts weight. For this specific application, a low moment of inertia is required in order to provide higher and fast acceleration to the machine shaft.

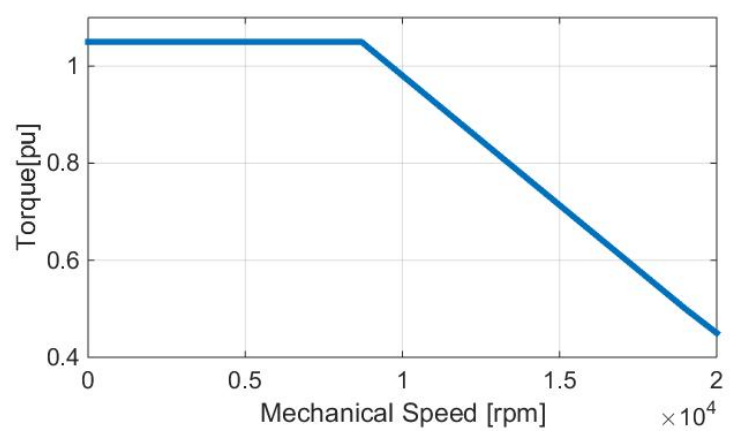

Fig. 1. Required torque-speed characteristics of the electrical machine 


\section{B. Power Converter and Control}

While, traditionally, the machine and the power electronic converter are usually developed as two separate units, however significant system level improvements can be achieved by considering their closely-related interactions. The DC-Link and the converter specifications can be considered as input parameters for the machine design. In this application, conventional Si IGBT technology has been selected for the power electronic converter, mainly due to the required high maturity level, suitable for the harsh environment, synonymous with this industrial application.

The main drawback in using IGBTs instead of wide bandgap devices (Sic or $\mathrm{GaN}$ ) is that the devices in the required range of power cannot usually be operated at switching frequencies higher than $16-18 \mathrm{kHz}$. Thus, for safety reasons, dead times need to be in the range of $2.5-3 \mu \mathrm{s}$. The effect of dead times, as well known from the literature, is to reduce the effective voltage applied to machine windings by a factor that can be considered proportional to the product of the dead time and the switching frequency. Additionally, they introduce distortion in the current waveforms, which if not properly compensated may increase machine losses due to high frequency harmonics. The distorting effects of dead times can be compensated in different ways, both using conventional techniques (e.g. adding an offset to the reference voltages proportional to the equivalent voltage loss [7]) or advanced techniques (e.g. synchronous frame filtering or resonant controllers use [8]). These techniques allow to reduce the distortions in the currents waveforms, in particular during the zero-crossing, leveraging the main control algorithm from this task. However, adding an offset or adding a high harmonic component (as the one obtained from resonant controller or synchronous frame filtering) means that the over modulation 'area' of the converter will be reached sooner that for an ideal converter without any dead time. Accordingly, the abovementioned voltage loss can be "reflected" to the DC-link value and taken into consideration for the machine design. Similar considerations can be done about voltage drops across power electronics devices (IGBTs and diodes).

Considering all the above, even if in the proposed application the DC-link voltage rated value is the conventional $270 \mathrm{~V}$, the machine has been designed considering the significantly lower voltage of $210 \mathrm{~V}$. This value comes from the previously discussed consideration about the converter characteristics and to compensate for other not modelled voltage losses due to cabling.

Another important factor to be considered is the ratio between machine fundamental frequency and the switching frequency. For high speed machines, such as for the application at hand, increasing the number of pole pairs means that this ratio will decrease, thus leading to consistent limitations in the control algorithm in compensating high harmonics in the high speed operation range of the drive. For this reason, particular attention has then to be put on the backEMF voltages spectra of the machine, trying to obtain a THD as lower as possible (as good practice) and directing the backEMF harmonics in the low frequencies range (ideally around the third or the ninth harmonic of the fundamental).
Based on those assumptions, the main design specifications are listed and summarized in Table 1.

TABLE 1. Design Specifications

\begin{tabular}{|c|c|c|}
\hline Parameters & Value & Units \\
\hline Dc link voltage & 210 & $\mathrm{Vdc}$ \\
\hline Max. current & $\leqq 85$ & $\mathrm{~A}$ \\
\hline THD of BEMF & $\leqq 5$ & - \\
\hline Moment of inertia & $\leqq 0.1 \times 10^{-3}$ & $\mathrm{~kg} \cdot \mathrm{m}^{2}$ \\
\hline Weight & $\leqq 2.5$ & $\mathrm{Kg}$ \\
\hline Stack length & $\leqq 85$ & $\mathrm{~mm}$ \\
\hline Axial cross section & $\leqq 70 \times 70$ & $\mathrm{~mm}$ \\
\hline Max. temperature & 210 & ${ }^{\circ} \mathrm{C}$ \\
\hline Ambient temperature & 90 & ${ }^{\circ} \mathrm{C}$ \\
\hline
\end{tabular}

\section{EleCtrical Motor Design}

Based on the information provided in the previous section and considering the specific application, different electrical machine topologies have been considered in [4] such as induction machine, switched reluctance machine, synchronous reluctance machine and permanent magnet synchronous machine in order to provide a qualitative comparison. A PMSM has been selected taking into account torque density, inertia, mechanical and thermal constraint and over all drive size [4]. From the Permanent Magnet machine topologies the surface mount topology retained by a sleeve is chosen due to its improved performance at high speed, higher torque density, less sensitivity to air gap and its flexibility in design.

Considering the above, the next step was to select the suitable configuration among the SMPM machines. Therefore, for the SMPM, different slot/pole combinations and winding configurations have been investigated for the specific application to satisfy the project requirements.

\section{A. Slot/Pole Combination}

The performance of PMSM machine was based on a finite element (FE) tool that combines FE with analytical equations plus a thermal network system. The geometry used for the machine design is fully parametrical with different variables and fixed parameters in order to optimize the performance of the motor. Due to the restricted space and mass constraint of the application, the first step of the design process focuses on the investigation of machines ability to satisfy the torque requirements over all the speed range. The slot/pole combinations considered during the trade-off study are list in table 2 .

TABLE 2. Slot/Pole Combination

\begin{tabular}{|c|c|c|c|c|c|}
\hline Pole & Slot & $\mathrm{q}$ & Pole & Slot & $\mathrm{q}$ \\
\hline 4 & 12 & 1 & 8 & 15 & $5 / 8$ \\
\hline 6 & 9 & 0.5 & 8 & 24 & 1 \\
\hline 6 & 18 & 1 & 10 & 12 & $2 / 5$ \\
\hline 6 & 27 & 1.5 & 10 & 18 & $3 / 5$ \\
\hline 6 & 36 & 2 & 10 & 21 & $7 / 10$ \\
\hline 8 & 9 & $3 / 8$ & 10 & 30 & 1 \\
\hline
\end{tabular}

$\mathrm{q}=$ number of slot per pole per phase. 
The trade-off study was focused on three-phase machines $(\mathrm{m}=3)$ and a number of poles lower than $10(2 p \leq 10)$, aiming to keep the machine fundamental frequency and consequently the converter switching losses to a reasonably low value. In each design of PMSM with different slot/pole combination, the machine geometrical parameters are roughly optimized to have a maximum average output torque. The maximum value of stator outer diameter OD $=70 \mathrm{~mm}$ and motor axial length $\mathrm{L}=85 \mathrm{~mm}$ are fixed by space dimensions of the project requirement. A fair comparison has been made by considering different number of turns in order to have the same peak value of the phase voltage induced for all machines, which is $\leq$ $V_{d c} / 2$. Fig. 2 shows the results, for different slot/pole combination on the average torque of PMSM at a fixed current density of $25 \mathrm{~A} / \mathrm{mm}^{2}$.

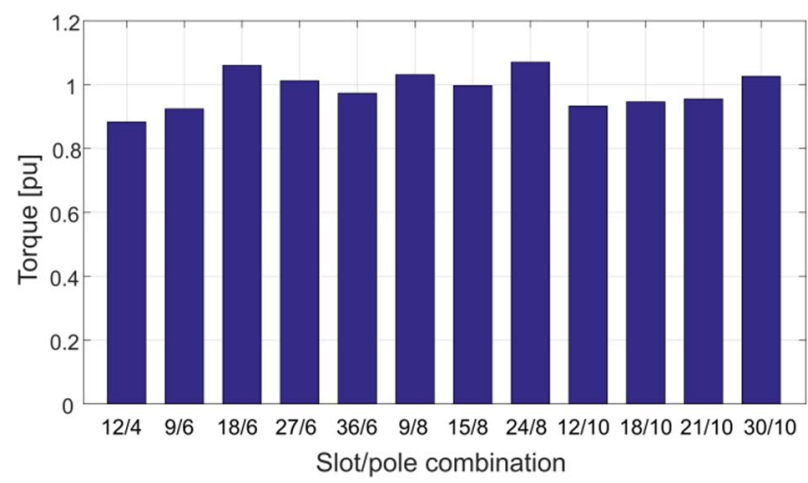

Fig. 2. Slot/pole combination comparison at $\mathrm{J}=25 \mathrm{~A} / \mathrm{mm}^{2}$

From Fig. 2, the $8 \mathrm{p} / 24 \mathrm{~s}$ machine has the highest torque of $10.75 \mathrm{Nm}$ but with higher value of torque ripple about $13.4 \%$. Therefore, it is also important to consider the winding configurations to obtain lower torque ripple, lower THD, lower losses and higher output torque.

\section{B. Winding Configurations}

Distributed windings such as those with $\mathrm{q}=1$ tend to have larger end windings and hence result in a longer motor for the same stack length. This leads to poorer rotor dynamics, higher copper losses and manufacturing issues for high pole numbers. On the other hand, they present a good fundamental winding factor and are free of sub-harmonics [6]. Concentrated windings (tooth-wound coils) offer lower motor length for the same core length and lower copper losses. However, due to the large MMF harmonic content they can produce a large amount of parasitic losses at high speeds and high electrical frequencies $[9,10]$. Due to the constraints on envelope dimensions of the machine (stack length), a double-layer configuration is preferred to single-layer windings due to its shorter end windings, lower torque ripple, losses and more sinusoidal back-EMF [2, 9]. Therefore, a comparative investigation on SMPM machines in terms of torque ripple, cogging torque and THD of the back-EMF for both distributed and concentrated topologies with double layer winding configuration for all slot/pole combination are shown in the Table 3.
Due to the limitation of the switching frequency (16/18 $\mathrm{kHz}$ ) of IGBTs, it is challenging to select high pole numbers. However, a pole number of 8 or less is likely to be optimal. It can be clearly seen that the 4 pole machine exhibits the highest torque ripple, THD and cogging torque. Therefore, a 4 pole machine is not considered. Among the 6-pole machines, $6 \mathrm{p} / 27 \mathrm{~s}$ offers the best performance in terms of lower torque ripple, cogging torque and total harmonic distortion while the highest average torque is achieved by $6 \mathrm{p} / 18 \mathrm{~s}$ due to its higher fundamental winding factor. Also, $6 \mathrm{p} / 36 \mathrm{~s}$ has been discarded due to the high number of slots (36), which is difficult to manufacture due to the small dimensions of this machine. The $6 \mathrm{p} / 9 \mathrm{~s}$ machine instead has the highest cogging torque and torque ripple and the lowest average torque, due to the smallest fundamental winding factor. From the 8 pole machines, $8 \mathrm{p} / 24 \mathrm{~s}$ has the highest average output torque but with higher torque ripple and THD. Also, this machine has a distributed (overlapping) winding configuration which results a longer end winding, while $8 \mathrm{p} / 15 \mathrm{~s}$ has the lowest fundamental winding factor. However, $8 \mathrm{p} / 9 \mathrm{~s}$ has the fractional slot per pole per phase which leads to shorter end winding and higher fundamental winding factor with lower torque ripple, THD and cogging torque.

TABLE 3. Winding layout characteristics

\begin{tabular}{|c|c|c|c|c|c|c|}
\hline \multicolumn{7}{|c|}{ All teeth wound (Double Layer) } \\
\hline P & S & $\begin{array}{c}\text { LCM } \\
(\mathrm{P}, \mathrm{S})\end{array}$ & $\begin{array}{c}\text { Winding } \\
\text { Factor }\end{array}$ & $\begin{array}{c}\text { THD } \\
(\%)\end{array}$ & $\begin{array}{c}\text { Torque } \\
\text { ripple (\%) }\end{array}$ & $\begin{array}{c}\text { T_cogging } \\
\text { ripple (Nm) }\end{array}$ \\
\hline 4 & 12 & 12 & 1 & 24 & 12.7 & 0.554 \\
\hline 6 & 9 & 18 & 0.866 & 4.26 & 21.18 & 0.546 \\
\hline 6 & 18 & 18 & 1 & 22 & 13.18 & 0.537 \\
\hline 6 & 27 & 54 & 0.945 & 13 & 2.55 & 0.009 \\
\hline 6 & 36 & 36 & 0.965 & 14.82 & 5.1 & 0.033 \\
\hline 8 & 9 & 72 & 0.945 & 4.62 & 2.16 & 0.012 \\
\hline 8 & 15 & 120 & 0.71 & 13.1 & 1.09 & 0.001 \\
\hline 8 & 24 & 24 & 1 & 22.34 & 13.4 & 0.344 \\
\hline 10 & 12 & 60 & 0.933 & 7.8 & 1.67 & 0.008 \\
\hline 10 & 18 & 90 & 0.735 & 9 & 1.08 & 0.002 \\
\hline 10 & 21 & 210 & 0.953 & 10.43 & 2.27 & 0.006 \\
\hline 10 & 30 & 30 & 1 & 15.44 & 9.58 & 0.297 \\
\hline
\end{tabular}

As a result, two different slot/pole combinations have been identified as capable to meet the project requirements. These pole/slot combinations are 8 pole 9 slot $(8 \mathrm{p} / 9 \mathrm{~s})$ and 6 pole 27 slot $(6 \mathrm{p} / 27 \mathrm{~s})$ :-

The 8 pole -9 slot double-layer concentrated winding with fractional slot per pole per phase $(q=0.375)$, shown in Fig. 3-a gives ease of manufacturing, a short end winding, lower copper losses, fault tolerance, higher fill factor and higher eddy-current losses in both (magnet and sleeve).

The 6 pole -27 slot double-layer distributed winding, as shown in Fig. 3-b presents lower eddy-current losses, a small torque ripple and a longer machine for the same stack length due to the longer end windings and higher copper losses, 


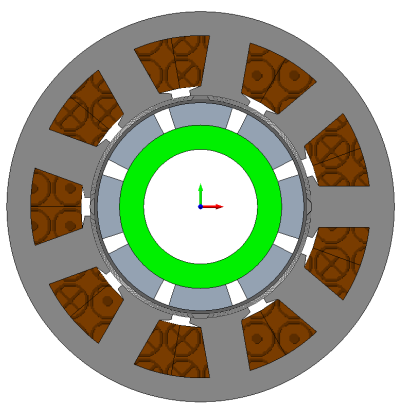

(a) $8 \mathrm{p} / 9 \mathrm{~s}$

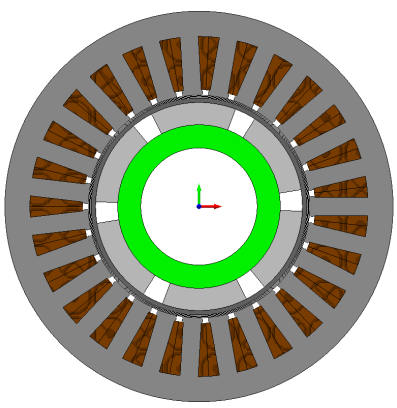

(b) $6 \mathrm{p} / 27 \mathrm{~s}$
Fig 3. Cross-section of the PMSM

\section{Thermal considerations}

Considering all the above, the $8 \mathrm{p} / 9 \mathrm{~s}$ PMSM has been selected, and the decision was also based on the thermal limitations of the machine. Due to the high power density of the application, an appropriate cooling and thermal management strategy was required. A special cooling system has been used where both the stator and rotor are completely flooded [3]. However, the main limitation was observed to be the cooling of the stator slots. Due to this, a system will customized cooling channels in the slot, as shown in Fig. 4, was proposed and investigated [3]. This technique was shown to be the most efficient way to remove the heat generated by the copper losses in the coil [3].

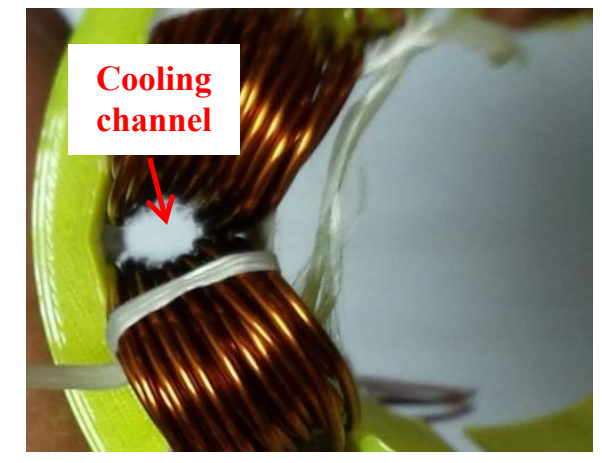

Fig 4. Cooling channels in a slot of a dummy stator of $8 \mathrm{p} / 9 \mathrm{~s}$ PMSM

The main challenge with implementing this technique is of course to find an optimal compromise between the space required for the channel and the reduced copper area. Thus, a detailed analysis of the proposed configurations was done. This is presented in detail in [3], where, it is shown that having a cooling channel inside the slot for $6 \mathrm{p} / 27 \mathrm{~s}$ PMSM is not feasible because of the smaller area of the slot. Also, because of the higher copper losses and longer end winding, which could block the oil from passing through the cooling channel, the $6 \mathrm{p} / 27 \mathrm{~s}$ configuration is not suitable for the application. The $8 \mathrm{p} / 9 \mathrm{~s}$ PM machine has shorter end-windings resulting in lower copper losses, higher efficiency and high torque density [9]. In addition this machine allows to have enough space for the cooling channel because of the higher slot area. Therefore, the 8p/9s SMPM machine with double layer (concentrated) winding has been considered for the rest of this work. It is well known [9, 10] that such a slot/pole combination presents high rotor losses due to the harmonicrich components for the armature reaction field. This indicates a topology whose performance is very sensitive to the air gap thickness dimension and attention must therefore be given to this aspect [10].

\section{IMPROVED MACHINE DESIGN}

In order to enhance the general performance of the machine and achieve the required torque, a number of strategies have been proposed. In this section the applied solutions are presented

\section{A. Changing the Stator Lamination Material}

Due to the high power density of the application, one of the main challenges is to limit the machine volume to the overall envelope and weight. In addition, the current density generated in slot is very high and its rms value is 37.2 $\mathrm{A} / \mathrm{mm}^{2}$. With such a high current density, the temperature generated inside the slot was $480^{\circ} \mathrm{C}$ which required a special cooling system. Therefore, a full flooded system with a slot water jacket, is selected for the machine cooling [3]. In order to reduce the total copper losses (max. temperature) a material with higher performance has been investigated.

The initial 8p/9s machine was optimized using Silicon Steel (SiFe) material (M270-35A), with lamination thickness of $0.35 \mathrm{~mm}$ and saturation limit of $1.7 T$. However, using Cobalt Iron (CoFe) material (VacoFlux 48) with lamination thickness of $0.1 \mathrm{~mm}$, the magnetic performance of the machine can be greatly improved, achieving saturation points of about 2.3T. In Fig. 5 the $\mathrm{BH}$ curve of both materials are reported and compared

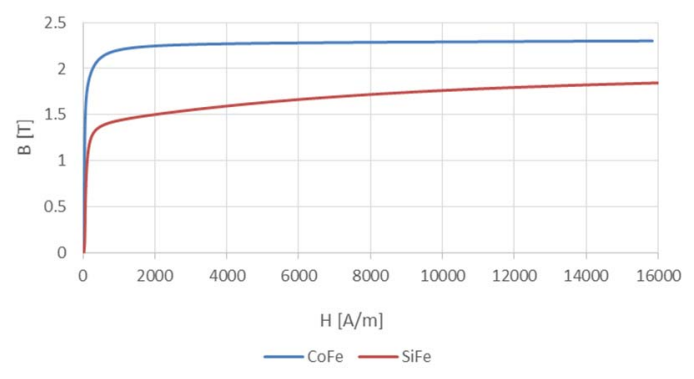

Fig.5. BH curve for the stator lamination material

CoFe material allows higher values of flux density through the tooth and back iron of the $8 \mathrm{p} / 9 \mathrm{~s}$ PMSM making the machine shorter and lighter compared to the one with Silicon Steel material (M270-35A) [11]. However, the main disadvantages associated with $\mathrm{CoFe}$ material is its higher price, availability on market and their mass density 8120 $\mathrm{kg} / \mathrm{m}^{3}$ compared to $7650 \mathrm{~kg} / \mathrm{m}^{3}$ for SiFe material [11].

Therefore, the $8 \mathrm{p} / 9 \mathrm{~s}$ machine has been optimized for the specific properties of CoFe material in order to improve the electromagnetic performance of the machine, which then allows us to use a reduced current density to reach the same torque performance. Figure 6 shows the field density map for two optimized FE models. With the CoFe material the area of the slot is increased by $22.3 \%$ compared to $\mathrm{SiFe}$ material. The results obtained for the two different designs are presented in Table 4 for fixed envelope dimensions and a constant fill factor of $37 \%$ of the slot area. 


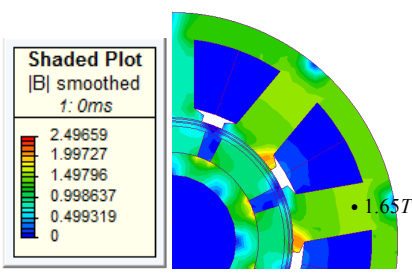

(a) $\mathrm{SiFe}$ material

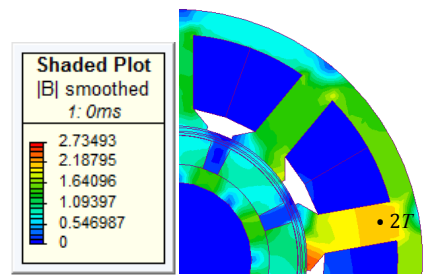

(b) $\mathrm{CoFe}$ material
Fig 6. Flux density map

TABLE 4. SiFe vs. CoFe performance comparisons for the same slot fill factor

\begin{tabular}{|c|c|c|}
\hline & $\mathrm{SiFe}$ & $\mathrm{CoFe}$ \\
\hline $\mathrm{T}(\mathrm{pu}) @ 8700 \mathrm{rpm}$ & 1.05 & 1.05 \\
\hline Current density J $\left(A / \mathrm{mm}^{2}\right)$ & 37.4 & 29.5 \\
\hline Total Copper losses $(\mathrm{W})$ & 1200 & 940 \\
\hline Mass $(\mathrm{kg})$ & 2.36 & 2.52 \\
\hline
\end{tabular}

From Table 4, it is clear that, for the same fill factor the machine design based on CoFe material provide lower copper losses compared to the machine design based on Silicon Steel material. The machine with Silicon steel laminations instead has lower mass thanks to the lower mass density of the SiFe material. Therefore, Cobalt iron material is adopted for this application. However, even with Cobalt Iron material it was found that the maximum temperature generated inside the slot still very high.

\section{B. Changing the Magnetization Structure of the PM}

The performance of the electrical machine has been further improved with the adoption of Halbach arrays [2]. This arrangement led to improve the air gap flux density with a more sinusoidal waveform which results in a more sinusoidal back-EMF, a lower torque ripple and lower iron losses, resulting in a higher torque $[2,12]$. Also, with Halbach arrays, other aspects of the machine, such as the rotor yoke can be significantly reduced [13]. The drawbacks related to this arrangement are the higher cost and complexity of manufacturing [2]. In this work, a quasi Halbach magnetized magnet is implemented into the PMSM as shown in Fig. 7, where the ratio between the transition pole and magnet pole has been optimized in order to reduce the THD, torque ripple and satisfy the torque requirement.

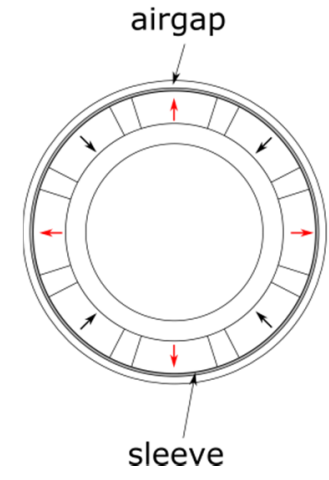

(a) Conventional SMPM array

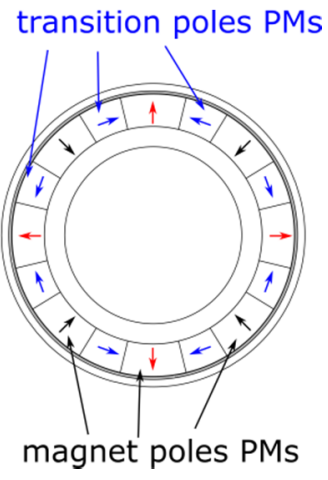

(b) Quasi-Halbach array
Fig 7. Sketch of $2 \mathrm{D}$ cross-section of the PMSM with different rotor PM magnetization
Compared with a conventional SMPM (radial magnetization), a quasi-Halbach array configuration presents a reduction of the total machine mass of $10 \%$, with a stack length decreased by $13.8 \%$. Thanks to this arrangement improvements in terms of reduction of $24.8 \%$ and $5.5 \%$ for the windage losses and rotor moment of inertia respectively, were achieved. While this results in a significant reduction by $10.58 \%$ of the copper losses, the temperature generated inside the slot is still quite high (about $230^{\circ} \mathrm{C}$ ). To mitigate this, a compromise between the optimal number of turns and the stack length has been identified with a total reduction of the motor axial length by $3 \%$. This result is also beneficial representing all the stringent project requirements such as total length, mass, inertia, dc-link voltage, current and the most important thing is the reduction in the total copper losses. In Table 5 the most important parameters of the final machine are presented for the two different operating conditions.

TABLE 5. General Machine Specifications

\begin{tabular}{|c|c|c|}
\hline Performance Indicators & $\begin{array}{c}1.05 \mathrm{pu} @ \\
8700 \mathrm{rpm}\end{array}$ & $\begin{array}{c}0.5 \mathrm{pu} @ \\
19000 \mathrm{rpm}\end{array}$ \\
\hline Current density $\mathrm{J}\left(\mathrm{A} / \mathrm{mm}^{2}\right)$ & \multicolumn{2}{|c|}{$26.6 \mathrm{RMS}$} \\
\hline Power density $(\mathrm{k} W / \mathrm{kg})$ & \multicolumn{2}{|c|}{3.7} \\
\hline Copper losses $(\mathrm{W})$ & 91.2 & 830 \\
\hline Efficiency $(\%)$ & 0.5 & 86.5 \\
\hline Torque ripple (\%) & 3.13 & 3.14 \\
\hline Back-EmF THD $(\%)$ & \multicolumn{3}{|c|}{$1 . e^{-4}$} \\
\hline Moment of inertia $\left(\mathrm{kg} . \mathrm{m}^{2}\right)$ & \multicolumn{2}{|c|}{} \\
\hline
\end{tabular}

\section{THERMAL PERFORAMCNES OF MACHINE}

The machine is cooled by oil flowing through cooling channels in slots and a gap between stator and rotor. A high windage loss at rotor surface is expected when a high speed machine is full of oil. As the motor is directly coupled with a high pressure pump and the oil pressure inside the motor will be high, a full flooded cooling design will simplify shaft rotating seal. The cooling performances of machine are checked for the best magnetic case which is 8poles/9slots machine. Table 6 shows a list of the loss distribution in the machine at $19000 \mathrm{rpm}$.

TABLE 6. Loss table at 19000RPM

\begin{tabular}{|c|c|c|c|c|c|c|}
\hline Losses & $\begin{array}{c}\text { Copper } \\
\text { Loss }\end{array}$ & $\begin{array}{c}\text { Stator Iron } \\
\text { Loss }\end{array}$ & $\begin{array}{c}\text { Magnet } \\
\text { Loss }\end{array}$ & $\begin{array}{c}\text { Sleeve } \\
\text { Loss }\end{array}$ & $\begin{array}{c}\text { Shaft } \\
\text { Loss }\end{array}$ & $\begin{array}{c}\text { Windage } \\
\text { Loss }\end{array}$ \\
\hline$(\mathrm{W})$ & 830 & 60.4 & 172.6 & 257.8 & 140.5 & 288 \\
\hline
\end{tabular}

From table 6, it can be observed that the major loss is the heat generated in the coil, due to the high current density. Cooling channels are thus implemented in the slots, as shown in figure 4, to remove the heat from the coil. The heat generated by the rotor is removed by the oil flow through the gap. Figure 8 shows the cooling channel configures for the machine, where it can be observed how one is near the bottom of the slot and the other one is close to the top of slot. The cooling channel diameter is $3.5 \mathrm{~mm}$. 

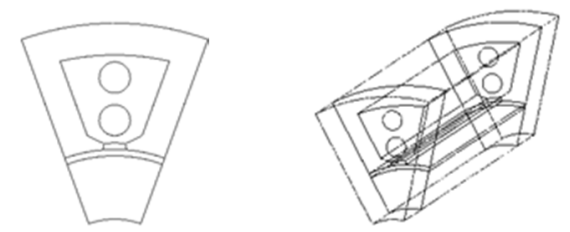

Fig 8. Cooling channels in a slot

The cooling performances are investigated using the lumped parameter thermal model of the commercial package MotorCad at various flow conditions. The worst case is when the cooling oil inlet reaches $90^{\circ} \mathrm{C}$ and flow rate of $4 \mathrm{~L} / \mathrm{min}$ and the machine speed at 19000rpm.
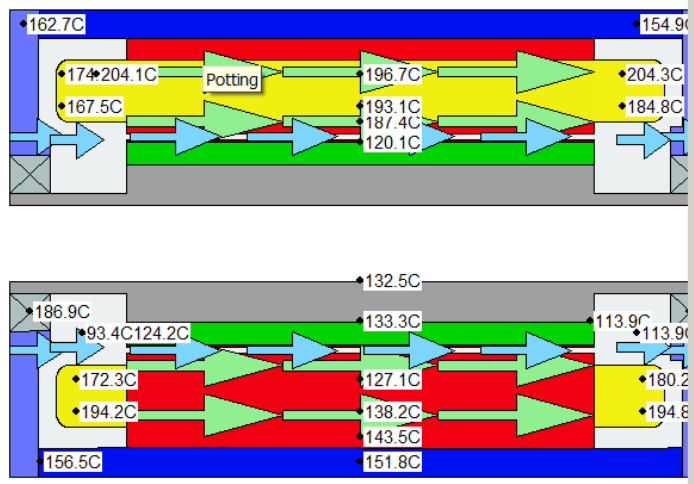

Fig. 9 Flow paths and temperature distribution at $90^{\circ} \mathrm{C}$ oil temperature

Figure 9 shows the oil flow paths inside the machine and a temperature distribution at the worst flow condition. Leaking oil from the oil pump is injected at the front of the motor and flows through the cooling channel in the stator slots and the gap between stator and rotor. At the worst case, the maximum temperature of the coil reaches $204.3^{\circ} \mathrm{C}$. The cooling channels inside the slot enable a better cooling at the center of the slots, while the temperature at the coil center is about $196.7^{\circ} \mathrm{C}$. This is within the machine specification of a maximum temperature of $210^{\circ} \mathrm{C}$. The maximum temperature of the PMs is found to be $133.3^{\circ} \mathrm{C}$, showing that it is far below the temperature limit of magnet. All this proves, that the machine can be thermally managed to the required levels by the oil available, even for the worst flow conditions.

\section{CONCLUSION}

This paper describes a trade-off analysis for high power density SMPM machine for a flooded industrial pump application. The performances of different designs have been analysed and compared including different slot-pole combinations and winding configurations. In order to achieve the required performance level for the $8 \mathrm{p} / 9 \mathrm{~s}$ PMSM and to improve the thermal limitation, several methodologies such as the use of Cobalt iron material and Halbach array have been investigated. It was clear that with the implementation of the above methodology an excellent performance of high torque with lower torque ripple and more sinusoidal back-EMF was achieved. In addition, a machine with a high power density of $3.7 \mathrm{~kW} / \mathrm{kg}$ was achieved for the considered motor application. A very important aspect of the design was the cooling channels created inside the slots. The rotor is cooled by oil flow through gap between stator and rotor. In the worst case of inlet oil condition, the maximum temperature of the machine is within the specifications.

In general it can be concluded that the design procedures presented in this paper have resulted in a machine design which satisfies the project requirements in terms of geometrical dimensions, weight and moment of inertia and respecting the thermal limitation. The next step for the project is machine manufacturing and testing.

\section{ACKNOWLEDGMENTS}

The work presented in this paper was partially supported by the 2013DFA70510 MoST International Cooperation.

\section{REFERENCES}

[1] M. Galea, C. Gerada, T. Raminosoa and P. Wheeler, "A Thermal Improvement Technique for the Phase Windings of Electrical Machines," in IEEE Transactions on Industry Applications, vol. 48, no. 1, pp. 79-87, Jan.-Feb. 2012.

[2] M. Galea, Z. Xu, C. Tighe, T. Hamiti, C. Gerada and S. Pickering, "Development of an aircraft wheel actuator for green taxiing," Electrical Machines (ICEM), 2014 International Conference on, Berlin, 2014, pp. 2492-2498.

[3] Z. Xu, A. Al-Timimy, M. Degano, P. Giangrande, G. Lo Calzo, He. Zhang, M. Galea, C. Gerada, S. Pickering and L. Xia, "Thermal Management of a Permanent Magnet Motor for a Directly Coupled Pump," Electrical Machines and Systems (ICEM), 2016 International Conference on Lausanne. Switzerland, (In press) 2016.

[4] A. Al-Timimy, M. Degano, P. Giangrande, G. Lo Calzo, Z. Xu, M. Galea, C. Gerada, He Zhang and L. Xia, "Design and Optimization of a High Power Density Machine for Flooded Industrial Application," Electrical Machines and Systems (ICEM), 2016 International Conference on Lausanne. Switzerland, (In press) 2016.

[5] W. Cao, B. C. Mecrow, G. J. Atkinson, J. W. Bennett and D. J. Atkinson, "Overview of Electric Motor Technologies Used for More Electric Aircraft (MEA)," in IEEE Transactions on Industrial Electronics, vol. 59, no. 9, pp. 3523-3531, Sept. 2012.

[6] C. Gerada, K. Bradley, C. Whitley and G. Towers, "High Torque Density PM Machines for High Performance Operation," Industrial Electronics Society, 2007. IECON 2007. 33rd Annual Conference of the IEEE, Taipei, 2007, pp. 210-215.

[7] N. Urasaki, T. Senjyu, K. Uezato and T. Funabashi, "Adaptive DeadTime Compensation Strategy for Permanent Magnet Synchronous Motor Drive," in IEEE Transactions on Energy Conversion, vol. 22, no. 2, pp. 271-280, June 2007.

[8] Y. Yang, K. Zhou, H. Wang and F. Blaabjerg, "Harmonics mitigation of dead time effects in PWM converters using a repetitive controller," 2015 IEEE Applied Power Electronics Conference and Exposition (APEC), Charlotte, NC, 2015, pp. 1479-1486.

[9] J. Gao, Y. Yu and S. Huang, "Winding layers and slot/pole combination in fractional slot/pole PMSM-Effects on motor performance," Electrical Machines and Systems, 2009. ICEMS 2009. International Conference on, Tokyo, 2009, pp. 1-4.

[10] D. Gerada, D. Borg-Bartolo, A. Mebarki, C. Micallef, N. L. Brown and C. Gerada, "Electrical machines for high speed applications with a wide constant-power region requirement," Electrical Machines and Systems (ICEMS), 2011 International Conference on, Beijing, 2011, pp. 1-6.

[11] M. Galea, T. Hamiti and C. Gerada, "Torque density improvements for high performance machines," Electric Machines \& Drives Conference (IEMDC), 2013 IEEE International, Chicago, IL, 2013, pp. 1066-1073.

[12] Yang Shen, "Novel Permanent Magnet Brushless Machines Having Segmented Halbach Array", PhD thesis, 15 November 2012, The University of Sheffield.

[13] M. Galea, L. Papini, H. Zhang, C. Gerada, and T. Hamiti, "Demagnetization Analysis for Halbach Array Configurations in Electrical Machines," Magnetics, IEEE Transactions on, vol. 51, pp. 19, 2015. 